\title{
Evaluation of 1,25(OH)2D3 Effects on FOXP3, ROR- $\gamma t$, GITR, and CTLA-4 Gene Expression in PBMCs of Vitamin D-Deficient Women with Unexplained Recurrent Pregnancy Loss
}

\author{
Elham Abdollahi ${ }^{1,2,3}$, Nafiseh Saghafi ${ }^{4}$, Seyed Abdolrahim Rahim Rezaee ${ }^{5,6}$, \\ Maryam Rastin ${ }^{7}$, Lida Jarahi ${ }^{8}$, Vicki Clifton $^{9}$ and Houshang Rafatpanah ${ }^{5,6^{*}}$
}

\begin{abstract}
${ }^{1}$ Halal Research Center of IRI, FDA, Tehran, Iran; ${ }^{2}$ Department of Medical Immunology and Allergy, Student Research Committee, School of Medicine, Mashhad University of Medical Sciences, Mashhad, Iran; ${ }^{3}$ Graduate Research Trainee in Mater Research Institute-University of Queensland, Translational Research Institute, South Brisbane, Australia; ${ }^{4}$ Department of Gynecology Oncology, Woman Health Research Center, Mashhad University of Medical Sciences, Mashhad, Iran; ${ }^{5}$ Research Center for HIV/AIDS, HTLV and Viral Hepatitis, Iranian Academic Center for Education, Culture and Research (ACECR), Mashhad Branch, Mashhad, Iran; ${ }^{6}$ Inflammation and Inflammatory Diseases Research Center, School of Medicine, Mashhad University of Medical Sciences, Mashhad, Iran; ${ }^{7}$ Immunology Research Center, BuAli Research Institute, Department of Immunology and Allergy, School of Medicine, Mashhad University of Medical Sciences, Mashhad, Iran; ${ }^{8}$ Department of Community Medicine, School of Medicine, Mashhad University of Medical Sciences Mashhad, Iran; ${ }^{9}$ Pregnancy and Development, Mater Research Institute, University of Queensland, Translational Research Institute, South Brisbane, Australia
\end{abstract}

Received 27 July 2019; accepted 3 September 2019; published online 23 February 2020

\begin{abstract}
Background: Vitamin D insufficiency and deficiency can be associated with adverse effects on fetus and pregnancy outcomes. This study aimed at evaluating the effect of 1,25VitD3 on specific transcription factor and markers of Tregs and Th17 cells in PBMCs of women with URPL as a case group and PBMCs of healthy women as a control group. Methods: Samples from 20 non-pregnant patients with a history of URPL were compared to 20 normal non-pregnant women. PBMCs were divided into three wells for each subject in the presence of 1,25VitD3 ( $50 \mathrm{nM}$, for 16 hours), PHA (10 $\mu \mathrm{M}$; positive control), and without any treatment (negative control). By Real-time PCR (Taqman assay), specific transcription factors of Tregs and Th17 cells, FOXP3, ROR- $y t$, GITR, and CTLA-4 mRNA expressions in two groups were measured. Results: FOXP3/ROR- $y t$ mRNA expression in PBMCs decreased significantly in women experiencing URPL compared to the control group $(p=0.0001)$. Although $1,25 V i t D 3$ (50 $\mathrm{nM})$ increased FOXP3 gene expression $(p=0.0001)$, it did not significantly affect $R O R$ - $y t$ gene expression. Besides, $1,25 \mathrm{VitD3}$ treatment significantly increased FOXP3/ROR- $y t$ mRNA expression from baseline in PBMCs of the fetal loss group compared to that of the control group $(p=0.01)$. The $1,25 \mathrm{VitD} 3$ also increased GITR gene expression $(p=0.017)$ in PBMCs of URPL women compared to the controls. Conclusion: Vitamin D deficiency may be a contributor to recurrent pregnancy loss and suggests that the supplementation of women with Vitamin $D$ pre-pregnancy may be protective against URPL via affecting Tregs signature genes, FOXP3 and GITR. DOI: 10.29252/ibj.24.5.290
\end{abstract}

Keywords: FOXP3, CTLA-4, 1,25VitD3

Corresponding Author: Houshang Rafatpanah

Immunology Research Center, Division of Inflammation and Inflammatory Diseases, Faculty of Medicine, Mashhad University of Medical Sciences,

Mashhad, Iran; Tel.: (+98-511) 8002376; E-mail: Rafatpanahh@mums.ac.ir

\section{List of Abbreviations:}

BMI, body mass index; CTLA-4, cytotoxic T lymphocyte-associated molecule-4; FOXP3, forkhead box P3; GITR, glucocorticoid-induced tumor necrosis factor receptor -related; PBMC, peripheral blood mononuclear cell; PHA, phytohemagglutinin; qRT-PCR, quantitative real-time RT-PCR; ROR-pt, retinoic acid-related orphan receptor $\gamma t$; Th, T helper; Tregs, regulatory T cells; URPL, unexplained recurrent pregnancy loss; VDR, vitamin D receptor 


\section{INTRODUCTION}

$\mathrm{F}$ Tetus is a semi-allogeneic graft; half of its major histocompatibility complex molecules comes from the mother and half from the father; therefore, fetus is antigenic, while the mother is immunologically responsive ${ }^{[1]}$. During pregnancy, the mother's immune system has to tolerate fetus, but once the immunological tolerance is broken down, recurrent pregnancy loss or spontaneous abortion may occur ${ }^{[1,2]}$. Recurrent fetal loss, recurrent pregnancy loss, recurrent miscarriage, habitual abortion, or recurrent spontaneous abortion are defined as three or more consecutive miscarriages prior to 20 weeks (or at the first trimester) of gestation ${ }^{[3-5]}$; approximately $1-5 \%$ of women have experienced recurrent pregnancy $\operatorname{loss}^{[6]}$. Although this event occurs due to several identifiable causes such as genetic, endocrine, anatomic and infectious agents, the etiology of nearly $50 \%$ of fetal loss causes is unexplained and still remains unknown; this situation is called $\mathrm{URPL}^{[7-10]}$.

There is a strong association between the failure of feto-maternal immunologic tolerance and recurrent pregnancy loss ${ }^{[11]}$. CD4 ${ }^{+} \mathrm{T}$ cells, which include $\mathrm{Th} 1$, Th2, Tregs, and Th17 cells, play an important role in the feto-maternal immune response. Maternal tolerance toward fetal alloantigens was explained by the predominant Th2-type immunity during pregnancy, while predominant Th1-type immune response was observed in recurrent pregnancy loss ${ }^{[12-15]}$. Th1/Th2 balance is not sufficient to define the mechanism toward tolerating the fetus. More recently, the emerging concept of the balance of Th17/Tregs has challenged the conventional paradigm of Th1/Th2 hypothesis ${ }^{[16-18]}$. Tregs $\left(\mathrm{CD}^{+} \mathrm{CD} 5^{+} \mathrm{FOXP3}^{+}\right)$ expressing CTLA-4 and GITR cells participate in the development and maintenance of tolerance in peripheral blood and tissues ${ }^{[8,19,20]}$. Parental antigens, human pregnancy hormones such as human chorionic gonadotropin, and chemokines are both involved in Tregs expansion ${ }^{[21]}$. FOXP3 is a master regulator of Tregs that is necessary for the development and function of Tregs. Deficiency of the FOXP3 gene suppresses the regulatory function of Tregs ${ }^{[11,22]}$. Tregs contribute to the successful pregnancy via suppressing self-reactive lymphocytes. The mechanisms of actions of Tregs are mediated by a cell-cell contact (CTLA-4) and the secretion of the key cytokines such as TGF- $\beta$ and IL-10 $0^{[23-26]}$.

Th17 $\left(\mathrm{CD} 4^{+} \mathrm{IL}-17 \mathrm{~A}^{+}\right)$cells are characterized by the expression of IL-17A, IL-17 F, IL-21, IL-22, IL-6, and TNF- $\alpha^{[27]}$. Th17 cells contribute to the host defense against both extracellular pathogens and fungal infections. $R O R-\gamma t$ is the specific transcription factor of
Th17 cells ${ }^{[28]}$. It has been demonstrated that IL-17 is involved in the initiation or progression of inflammatory and autoimmune diseases and transplant rejection in humans ${ }^{[29,30]}$. Th17 cells are regulated by Tregs that play a fundamental role in the establishment and maintenance of tolerance ${ }^{[31]}$. Th17 cells have been reported to be likely involved in the induction of inflammation in the late but not in the early stage of abortion $^{[32,33]}$. In the context of pathogenesis of URPL, several studies have evaluated the Th17/Tregs balance in peripheral blood, while it has been documented that local immune responses have a unique function in the fetal loss pathogenesis ${ }^{[16,34-38]}$.

The active form of $1,25 \mathrm{VitD} 3,1,25(\mathrm{OH}) 2 \mathrm{D} 3$, is a prohormone that regulates calcium hemostasis ${ }^{[39]}$. Conversion of vitamin D into its biologically active form, $1,25 \mathrm{VitD} 3\left(1,25-\mathrm{OH}\right.$ vitamin $\left.\mathrm{D}_{3}\right)$, starts in the skin and completes in the kidney by renal tubule cells $^{[40]}$. Meanwhile, 1,25VitD3 facilitates fertilization and implantation through immunomodulatory effects at the maternal-fetal interface, promoting adequate levels of inflammatory response for decasualization and implantation, which results in successful pregnancy ${ }^{[41,42]}$. The deficiency of $1,25 \mathrm{VitD} 3$ has been associated with a higher incidence of miscarriage, preeclampsia, subfertility, infertility, and pathological alterations of critical reproductive tissues such as the endometrium $^{[43]}$. Its deficiency is also related to gestational diabetes, bacterial vaginosis, and impaired fetal, and childhood growth and development ${ }^{[39]}$. It has been proposed that $1,25 \mathrm{VitD} 3$ influences pregnancy outcomes through its immunomodulatory impacts mediated by the VDR, a nuclear receptor, regulating gene transcription in immune cells and decidua ${ }^{[4-46]}$. In particular, 1,25VitD3 may regulate Th17/Tregs balance via altering the expression pattern of different genes related to these cells ${ }^{[47]}$.

The immune mechanisms of vitamin D effects on URPL have not yet been known completely. The placenta, ovaries, and decidua can express VDR mRNA and protein during the pregnancy ${ }^{[46]}$. In the context of immunomodulatory role of $1,25 \mathrm{VitD} 3$ in pregnancy, since a successful pregnancy is dependent on anti-inflammatory responses, it has been suggested that $1,25 \mathrm{VitD} 3$ could potentially be an effective treatment in URPL patients due to its immunomodulatory properties ${ }^{[48,49]}$. Indeed, Bubanovic $^{[48]}$, for the first time, showed that $1,25 \mathrm{VitD} 3$ acts as a new potential immunotherapy agent for recurrent miscarriage patients via downregulation of TNF- $\alpha$, IL-2, and IFN- $\gamma$ transcription. Very recently, it has been indicated that the supplements of vitamin $\mathrm{D}$ could increase the percentage of Tregs and FOXP3 gene expression while 
decrease the percentage of Th17 cells and ROR-yt gene expression in vivo ${ }^{[50]}$. The effects of $1,25 \mathrm{VitD} 3$ on GITR and CTLA-4 genes expression has not yet been evaluated in in vivo or in vitro conditions. To the best of our knowledge, this is the first study evaluating the imunoregulatory effects of 1,25VitD3 on GITR and CTLA-4 gene expressions in PBMCs of women with URPL. We also assessed FOXP3 and ROR- $\gamma t$ genes expression concurrently with GITR and CTLA-4 gene expressions.

\section{MATERIALS AND METHODS}

\section{Patients}

This case-control study was performed at the Mashhad University of Medical Sciences, Mashhad, Iran from 2017 to 2018. Participants included in the study were 20 women with a history of URPL as a case group and 20 fertile non-pregnant women with the history of normal deliveries (without miscarriage history) as a control group. The case and the control subjects were matched for age and BMI. For all patients and controls, at least 3 months had passed from the last fetal loss or successful pregnancy, respectively. The women in the case group did not have any other known medical conditions. Male partners underwent semen analyses; the number, shape, and movement of sperm were measured and were found to be normal. Both URPL and control groups were at reproductive age with regular menstruation, a normal BMI, non-pregnant as confirmed by a negative blood human chorionic gonadotropin test, and without any uterine, cervical, or genetic abnormalities.

Women were excluded from the current study if they had a positive screening tests, including hormone tests, Treponema pallidum particle agglutination assay, human immunodeficiency virus, hepatitis B virus, hepatitis $\mathrm{C}$ virus, male and female karyotypes, antinuclear antibodies, anti-cardiolipin antibodies, lupus anticoagulant antibodies, antiphospholipid antibodies, fewer than three consecutive miscarriages, a positive infectious test, no deficiency in $1,25 \mathrm{VitD} 3$ serum level, or recent consumption of $1,25 \mathrm{VitD} 3$ supplement.

\section{Inclusion criteria}

Inclusion criteria included a negative or normal result in the routine test panel, including hormone tests, male and female karyotypes, antinuclear antibodies, antiphospholipid antibodies, anti-cardiolipin antibodies, and lupus anticoagulant antibodies. Those women who were deficient in 1,25VitD3 (less than 20 $\mathrm{ng} / \mathrm{ml}$ ) and had not consumed 1,25VitD3 supplement in the past three months were included in the study.

\section{Isolation of PBMCs and cell culture}

Blood samples $(\approx 10 \mathrm{ml})$ were collected from each individual at days 17-23 of the menstrual cycle and then diluted 1:1 with PBS ( $\mathrm{pH} 7.4$, Sigma Aldrich, USA). PBMCs were isolated from whole blood via density gradient centrifugation using the FicollHypaque (Cedarlane, Toronto, Canada). Supernatants were washed twice with PBS, re-suspended at $1 \times 10^{6}$ PBMCs/ml in RPMI 1640 medium (BioSera, London, UK) containing $100 \mu / \mathrm{ml}$ of streptomycin, $100 \mu / \mathrm{ml}$ of penicillin, and $2 \mathrm{mM}$ of glutamine and finally assessed for viability by Trypan blue exclusion.

\section{Optimization of $1,25 \mathrm{VitD} 3$ concentration by flow cytometry assay}

To optimize vitamin D concentration, PBMCs of three patients with unexplained recurrent fetal loss were cultured in the presence of 0 (control), 10, 30, 50, and $100 \mathrm{nM}$ of 1,25VitD3. Flow cytometry assessment was used for the analysis of Tregs and Th17 cells (FACS Calibur, Becton Dickinson, San Jose, CA, USA) in different time points $(2,8,10,12,16,24$, and 48 hours). For cell culture experiments, treatment with $50 \mathrm{nM}$ of vitamin D for 16 hours was selected as optimum for further study (data not shown). For doing the experiments, sets of $1 \times 10^{6} \mathrm{PBMCs} /$ patient or control were placed in each well of sterile polystyrene plates for each subject (in the case and the control groups). The experiments were conducted on uncultured PBMCS, 1,25VitD3-treated PBMCs (50 $\mathrm{nM}$ for 16 hours, Sigma Aldrich), and PHA (10 $\mu \mathrm{M}$ for 16 hours, Gibco, USA) or with the media only (as a negative control).

\section{qRT-PCR}

Total RNA was extracted from PBMCs using RNA extraction kit (Invitek, Germany) according to the instructions of the manufacturer. Reverse transcriptions were carried out by oligo(dT) primers using RevertAid $^{\mathrm{TM}} \mathrm{H}$ (Germany) primers, and probes were designed using Express software (Applied Biosystems, USA). Primer and probes specificity was checked by BLAST analysis. The sequences of the primers and probes are shown in Table 1. The quality of RNA was checked by the electrophoresis on $2 \%$ agarose gel, and the $28 \mathrm{~S}, 18 \mathrm{~S}$, and $5.8 \mathrm{~S}$ bands were evaluated using a UV transilluminator. The cDNA $(2 \mu \mathrm{L})$ was amplified by real-time PCR in a final volume of $20 \mu \mathrm{L}$ containing $10 \mu \mathrm{L}$ of real-time PCR Master Mix (Takara, Japan), $0.3 \mu \mathrm{L}$ of each primer, $0.3 \mu \mathrm{L}$ of TaqMan probe, and 7.1 $\mu \mathrm{L}$ of RNase-free water using Taqman method by LightCycler $90^{\circledR}$ Roch Real-Time PCR System. PCR reaction was performed as follows: $10 \mathrm{~min}$ at $95^{\circ} \mathrm{C}$, followed by 45 cycles of $15 \mathrm{~s}$ at $95^{\circ} \mathrm{C}$, 
Table 1. Primer and probe sequences used in qRT-PCR

\begin{tabular}{|c|c|c|}
\hline Target gene & Sequence (5' to $\left.3^{\prime}\right)$ & $\begin{array}{c}\text { Product } \\
\text { length (bp) }\end{array}$ \\
\hline $\mathrm{ROR}-\gamma \mathrm{t}$ & $\begin{array}{l}\text { Forward: 5'-GCTAGGTGCAGAGCTTCAGG-3' } \\
\text { Reverse: 5'-TGTTCTCATGACTGAGCCTTGG-3' } \\
\text { Probe: FAM-CCTTGGCTCCCTGTCCTTCTCAGCA-BHQ }\end{array}$ & 145 \\
\hline FOXP3 & $\begin{array}{l}\text { Forward: 5'-RACTACTTCAAGTTCCACAACATGCR-3' } \\
\text { Reverse: 5'-RGAGTGTCCGCTGCTTCTCTG-3' } \\
\text { Probe: FAM-RTCACCTACGCCACGTTCATCCGCTR-BHQ }\end{array}$ & 95 \\
\hline$\beta 2 \mathrm{M}$ & $\begin{array}{l}\text { Forward: 5'-TTGTCTTTCAGCAAGGACTGG-3' } \\
\text { Reverse: 5'-CCACTTAACTATCTTGGGCTGTG-3' } \\
\text { Probe: FAM-TCACATGGTTCACACGGCAGGCAT-BHQ }\end{array}$ & 127 \\
\hline CTLA-4 & $\begin{array}{l}\text { Forward: 5'- CCCTGTCTTCTGCAAAGCAATGCA -3' } \\
\text { Reverse: 5'- CAGCCTGCCGAAGCACTGTCA -3 } \\
\text { Probe: FAM-TCCTCGCCCGAAGAGCGCGG-BHQ }\end{array}$ & 114 \\
\hline GITR & $\begin{array}{l}\text { Forward: 5'-GACGAGTTTGTGGACTCCTTTAAG-3' } \\
\text { Reverse: 5'-CCTGCCCAAGTTCCGATCC-3' } \\
\text { Probe: FAM-TCCTCGCCCGAAGAGCGCGG-BHQ }\end{array}$ & 129 \\
\hline
\end{tabular}

$30 \mathrm{~s}$ at $57^{\circ} \mathrm{C}$ and finally $1 \mathrm{~min}$ at $60^{\circ} \mathrm{C}$. Six-point 10 fold dilution standard curves were generated for FOXP3, ROR- $\gamma t$, CTLA-4, GITR, using the logarithmic dilution series of the total RNA. B2M was included as the reference gene. The relative quantity of each mRNA was normalized to the relative quantity of $\beta 2 \mathrm{M}$ mRNA.

\section{Statistical analysis}

All statistical analyses were carried out using the SPSS 16.0 software and Graphpad Prism 5.0. Data were presented as mean $\pm \mathrm{SE}$. For comparisons of the mean data, parametric $t$-test and ANOVA were performed. $p$ value of less than 0.05 was considered statistically significant.

\section{Ethical statement}

The above-mentioned sampling protocols were approved by the Research Ethics Committee of
Mashhad University of Medical Sciences, Mashhad, Iran (ethical code: 961711). Written informed consents were provided by all the patients.

\section{RESULTS}

Clinical characteristics of the patients with recurrent fetal loss are shown in Table 2. Based on the Table, there were no significant differences in age and BMI between the two groups. The mean age and BMI of the patients with unexplained recurrent fetal loss were 23.3 \pm 6.00 and $24.3 \pm 5.00$ years, and those of the control group were $25.6 \pm 6.00(p=0.71)$ and $23.5 \pm 6.03(p=$ $0.51)$, respectively. Sex hormones levels in the studied groups are represented in Table 3. There were no significant differences in the serum level of progesterone, estradiol, prolactin, FSH, or LH between the case and control groups.

Table 2. Clinical characteristics of women with URPL

\begin{tabular}{lcc}
\hline Clinical characteristics & $\begin{array}{c}\text { Control } \\
(\mathbf{n = 2 0})\end{array}$ & $\begin{array}{c}\text { Patients with unexplained } \\
\text { recurrent fetal loss }(\mathbf{n}=\mathbf{2 0})\end{array}$ \\
\hline Age $(\mathrm{y})$ & $23.3 \pm 6.00$ & $24.3 \pm 5.0$ \\
BMI & $24.3 \pm 6.00$ & $23.5 \pm 6.03$ \\
Mean of miscarriage & 4 (rang=3-6 miscarriage) & - \\
Mean of time of miscarriage (week of gestation) & 6.4 & - \\
Mean of time of last miscarriage (months passed & 9.2 & - \\
from last miscarriage) & & 33.3 \\
Blood group (\%) & & 22.2 \\
A & 15.8 & 11.1 \\
B & 47.4 & 33.3 \\
AB & 10.5 & \\
O & 26.3 & \\
\hline
\end{tabular}


Table 3. Sex hormones levels in the case and control group

\begin{tabular}{lccc}
\hline Hormone & $\begin{array}{c}\text { Case group } \\
(\mathbf{n = 2 0})\end{array}$ & $\begin{array}{c}\text { Control group } \\
(\mathbf{n = 2 0})\end{array}$ & $\begin{array}{c}\boldsymbol{p} \\
\text { value }\end{array}$ \\
\hline E2 $(\mathrm{pg} / \mathrm{ml})$ & $217.8 \pm 141.5$ & $221.8 \pm 156$ & 0.464 \\
Progesterone $(\mathrm{ng} / \mathrm{ml})$ & $5.3 \pm 6.8$ & $5.9 \pm 6.2$ & 0.579 \\
Prolactin $(\mathrm{ng} / \mathrm{ml})$ & $20.7 \pm 22.8$ & $19.5 \pm 20.6$ & 0.365 \\
FSH $(\mathrm{mIU} / \mathrm{ml})$ & $5.9 \pm 3.7$ & $4.5 \pm 2.8$ & 0.573 \\
LH $(\mathrm{mIU} / \mathrm{ml})$ & $14.9 \pm 16.2$ & $14.1 \pm 18.3$ & 0.854 \\
\hline
\end{tabular}
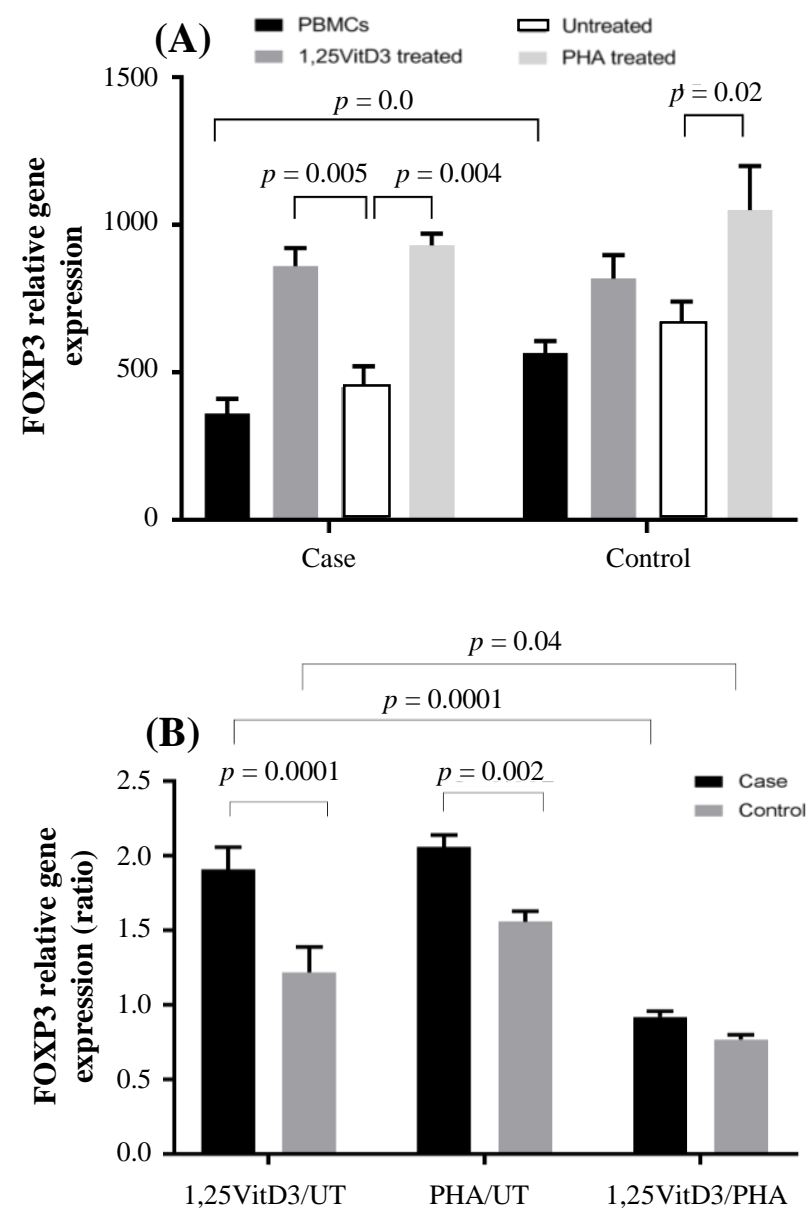

Fig. 1. FOXP3 gene expression. FOXP3 gene expression (A) and its ratio (B) in the presence of $1,25 \mathrm{VitD} 3$, PHA (as a positive control), and negative control (as a baseline) in PBMCs of patients with URPL and the controls. UT, untreated

\section{Expression of Tregs and Th17 transcription factors in PBMCs}

The expressions of FOXP3 and ROR- $\gamma \mathrm{t}$ genes were measured in PBMCs of the unexplained recurrent fetal loss group and control group by qRT-PCR.

Expressions of these transcription factors were then divided by reference gene (B2M) to normalize the results and reach a normalized index for each gene of interest for each sample. FOXP3 gene expression decreased significantly in patients with fetal loss compared to the control group $(360.60 \pm 50.50$ vs. $565.95 \pm 40.36$; $p=0.02$; Fig. 1A). Gene expression index of ROR- $\gamma t$ in PBMCs of URPL women was nonsignificantly higher than the control group (316.41 \pm 150.99 vs. $148.94 \pm 50.21 ; p>0.05$; Fig. $2 \mathrm{~B}$ ). Our results also showed that $F O X P 3 / R O R-\gamma t$ ratio was significantly lower in PBMCs of the case group than that of the control group $(1.13 \pm 0.3$ vs. $3.79 \pm 0.8 ; p=$ 0.0001; Fig. 3A).

\section{Expression of Tregs markers in PBMCs}

GITR gene expression in PBMCs of patients with URPL decreased compared to the controls, but this change was not significant (1891.60 \pm 479.14 vs. $2647.3 \pm 483.39$; $p>0.05$; Fig. 4A). There was also no significant difference in CTLA-4 gene expression in PBMCs treatment with $1,25 \mathrm{VitD} 3$ between cells from women with fetal loss and the control group (311.21 \pm 78.65 vs. $307.11 \pm 67.39 ; p>0.05$; Fig. 5A).

\section{Effects of 1,25VitD3 on the expression of Tregs and Th17 transcription factors in PBMCs}

Our results showed that PBMCs treatment with 1,25VitD3 increased FOXP3 gene expression from the baseline (untreated PBMCs) in women with URPL compared to the controls $(1.91 \pm 0.15$ vs. $1.22 \pm 0.1 ; p$ $=0.0001$; Fig. 1B). The greater effect of 1,25VitD3 on FOXP3 gene expression in PBMCs of women with URPL may be related to the impairment of Tregs function in women with URPL, which could be strengthen by the treatment of PBMCs with 1,25VitD3 in such women. In the case group, there was a significant increase in FOXP3 gene expression in the PBMCs in the presence of 1,25VitD3 in comparison with the untreated PBMCs $(860.84 \pm 60.89$ vs. 450.02 $\pm 70.47 ; p=0.005$; Fig. $1 \mathrm{~A})$. In the control group, no significant change was observed in FOXP3 gene expression in the PBMCs in the presence of $1,25 \mathrm{VitD} 3$ in comparison with the untreated PBMCs (817.97 \pm 80.51 vs. $670.47 \pm 70.55 ; p>0.05$; Fig. 1A). There was also no significant difference in $R O R-\gamma t$ gene expression in treatment with $1,25 \mathrm{VitD} 3$ between cells from women with fetal loss and the control group (0.98 \pm 0.06 vs. $0.87 \pm 0.04 ; p>0.05$; Fig. $2 B$ ). In the case 

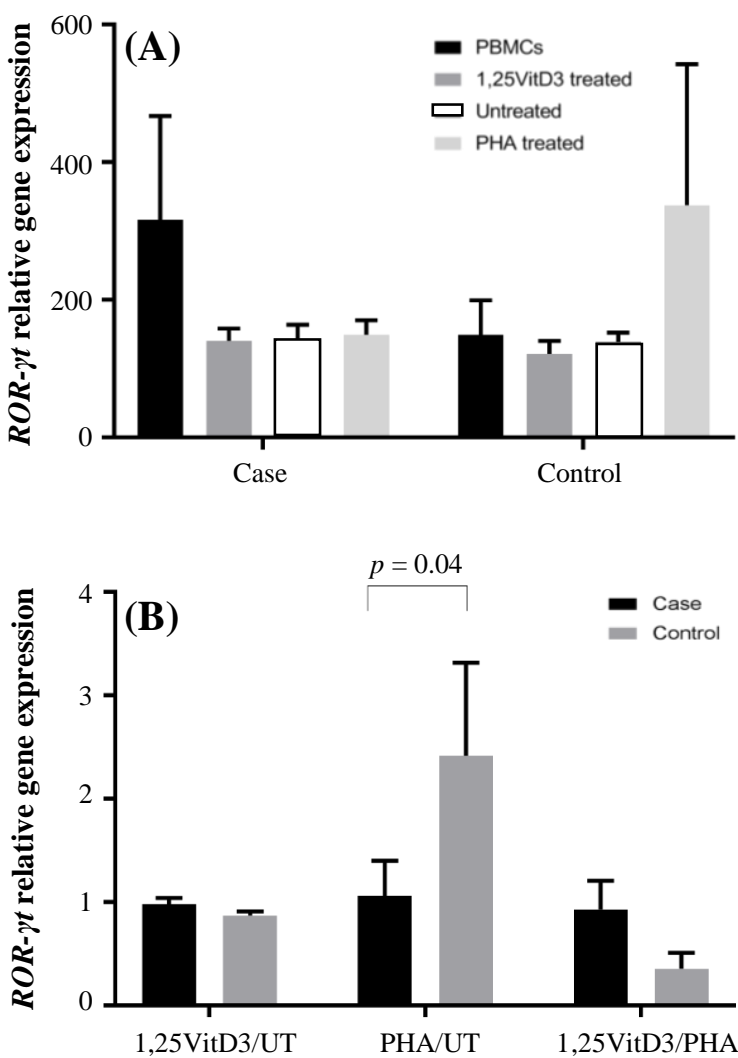

Fig. 2. ROR- $\gamma \mathrm{t}$ gene expression. ROR- $\gamma \mathrm{t}$ gene expression (A) and its ratio (B) in the presence of $1,25 \mathrm{VitD} 3$, PHA (as a positive control), and negative control (as a baseline) in PBMCs of patients with URPL and the controls. UT, untreated

and control groups, no significant changes was found in $R O R-\gamma t$ gene expression in the PBMCs in the presence of $1,25 \mathrm{VitD} 3$ in comparison with the untreated PBMCs $(140.09 \pm 18.00$ vs. $142.24 \pm 21.39$ and $121.25 \pm 19.00$ vs. $138.99 \pm 13.47$, respectively; $p$ $>0.05$; Fig. 2A). The 1,25VitD3 significantly affected FOXP3/ROR- $\gamma t$ ratio in PBMCs women with URPL compared to that of the controls $(1.94 \pm 0.50$ vs. $1.40 \pm$ $0.42 ; p=0.01$; Fig. 3B). PHA was used as a positive control and demonstrated that the cells are responsive to a stimulus, and that response does not vary between the groups.

\section{Effects of 1,25VitD3 on the expression of Tregs markers in PBMCs}

The results indicated that GITR gene expression increased in the presence of 1,25VitD3 from baseline (untreated PBMCs) in the peripheral blood in patients with fetal loss $(3.05 \pm 0.51$ vs. $0.59 \pm 0.10 ; p=0.017$; Fig. 4B). In the case group, there was a significant increase in GITR gene expression in the PBMCs in the presence of $1,25 \mathrm{VitD} 3$ as compared with the untreated PBMCs $(5700.47 \pm 681.89$ vs. $1863.02 \pm 700.47 ; p=$ 0.005; Fig. 4A). In the control group, no significant shift was found in $F O X P 3$ gene expression in PBMCs in the presence of $1,25 \mathrm{VitD} 3$ in comparison with the untreated PBMCs $(433.30 \pm 90.10$ vs. $723.63 \pm 150.03$; $p>0.05$; Fig. 4A). The 1,25VitD3 non-significantly increased the gene expression of CTLA-4 in the fetal loss group compared to the control group $(2.07 \pm 0.94$ vs. $0.95 \pm 0.21 ; p>0.05$; Fig. $5 \mathrm{~B}$ ). PHA, as a positive control, demonstrated that the cells are responsive to a stimulus, and that response does not vary between the groups. In the case and control groups, there were no significant changes in CTLA-4 gene expression in the PBMCs in the presence of $1,25 \mathrm{VitD} 3$ in comparison with the untreated PBMCs $(623.27 \pm 191.80$ vs. 299.74 \pm 72.50 and $393.85 \pm 78.04$ vs. $412.28 \pm 169.68$, respectively; $p>0.05$; Fig. 5A).
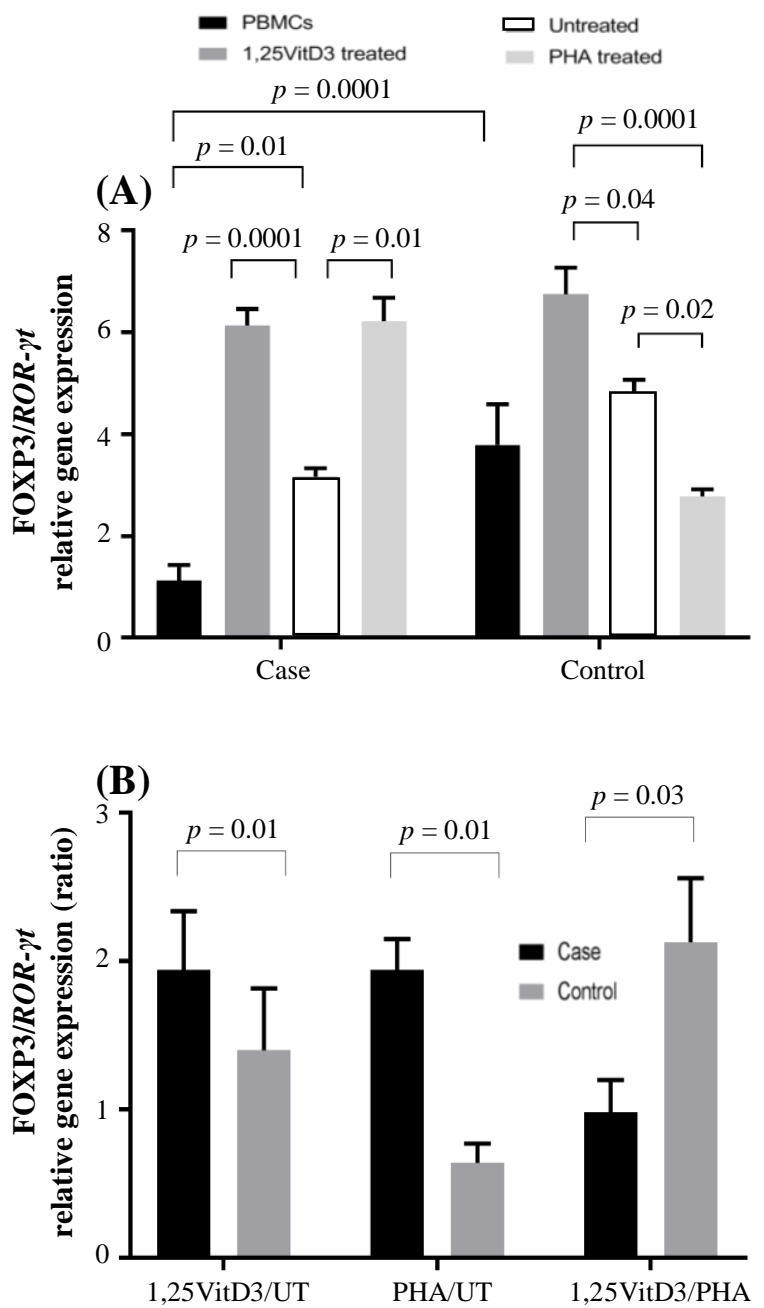

Fig. 3. $F O X P 3 / R O R-\gamma t$ gene expression. FOXP3/ROR- $\gamma \mathrm{t}$ gene expression (A) and its ratio (B) in the presence of 1,25VitD3, PHA (as a positive control), and negative control (as a baseline) in PBMCs of patients with URPL and the controls. UT, untreated 

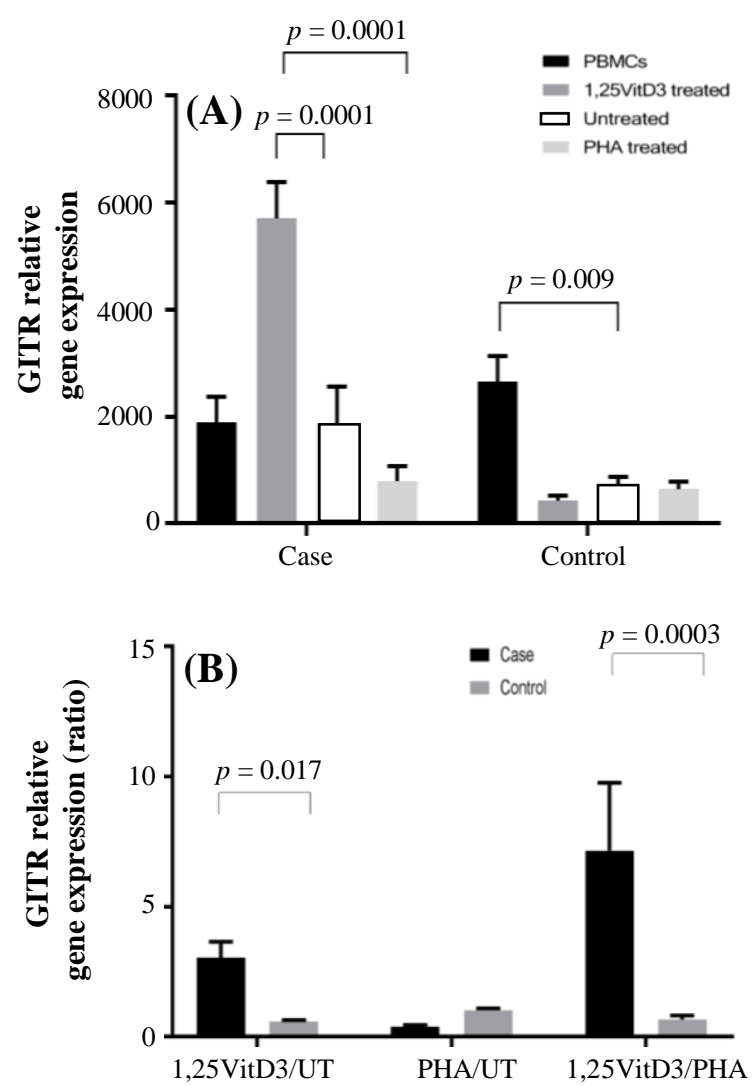

Fig. 4. GITR gene expression. GITR gene expression (A) and its ratio (B) in the presence of $1,25 \mathrm{VitD} 3$, PHA (as a positive control), and negative control (as a baseline) in PBMCs of patients with URPL and the controls. UT, untreated

\section{Correlation between FOXP3 and CTLA-4 gene expression}

There was a direct significant correlation between FOXP3 and CTLA-4 in the control group $(p=0.01, \mathrm{R}=$ 0.55 , Fig. 6).

\section{DISCUSSION}

Fetus is an allograft to the maternal host during early pregnancy, and failure in immune tolerance can lead to fetal loss ${ }^{[51,52]}$. Alteration of Tregs/Th17 balance in patients with fetal loss causes a rise in inflammatory responses that play a probable role in the pathogenesis of fetal loss ${ }^{[53-55]}$.

Tregs $\left(\mathrm{CD} 4^{+} \mathrm{CD} 25^{+}\right.$high $\left.\mathrm{FOXP}^{+}\right)$expressing $C T L A-$ 4 and GITR are necessary to mediate maternal tolerance to the fetus ${ }^{[56]}$. Previous studies have shown an increasing number of Tregs in peripheral blood, and decidua was due to the recognition of the semi allograft fetus antigens by Tregs, a process resulting in Tregs expansion ${ }^{441,57-59]}$. In both mice and humans, it has been supposed that the highest percentage of Tregs would reach the second trimester of pregnancy and then diminish in the postpartum period ${ }^{[38,57,60,61]}$. Defects in the numbers or functions of Tregs have been observed in women with recurrent pregnancy loss and mouse models in peripheral blood as well as in deciduas $^{[8,37,40,59,61,62]}$. Human TH17 cells producing IL-17 may have a major role in rejecting fetal antigens and, therefore, may be harmful to the maintenance of pregnancy ${ }^{[35,63,64]}$. ROR- $\gamma t$, as a specific transcription factor of Th17 cells, is required for the initiation and stabilization of the Th17 phenotype ${ }^{[28]}$.

In the context of immunomodulatory role of $1,25 \mathrm{VitD} 3$ in pregnancy, since a successful pregnancy is dependent on anti-inflammatory responses, it has been suggested that $1,25 \mathrm{VitD} 3$ could potentially be an effective treatment in URPL patients due to its immunomodulatory properties ${ }^{[48,49]}$.

For our study, we analyzed the expression of FOXP3, as a master regulator of Tregs, two surface markers of these cells (GITR and CTLA-4), and ROR$\gamma t$, as Th17 cells transcription factor, in PBMCs of URPL women and women with the history of at least successful pregnancy as a control group.

We showed that FOXP3 gene expression decreased significantly in peripheral blood in woman with URPL, while there was no significant change in $R O R-\gamma t$ gene expression compared to the controls. FOXP3/ROR- $\gamma t$ ratio was significantly lower than that of PBMCs of
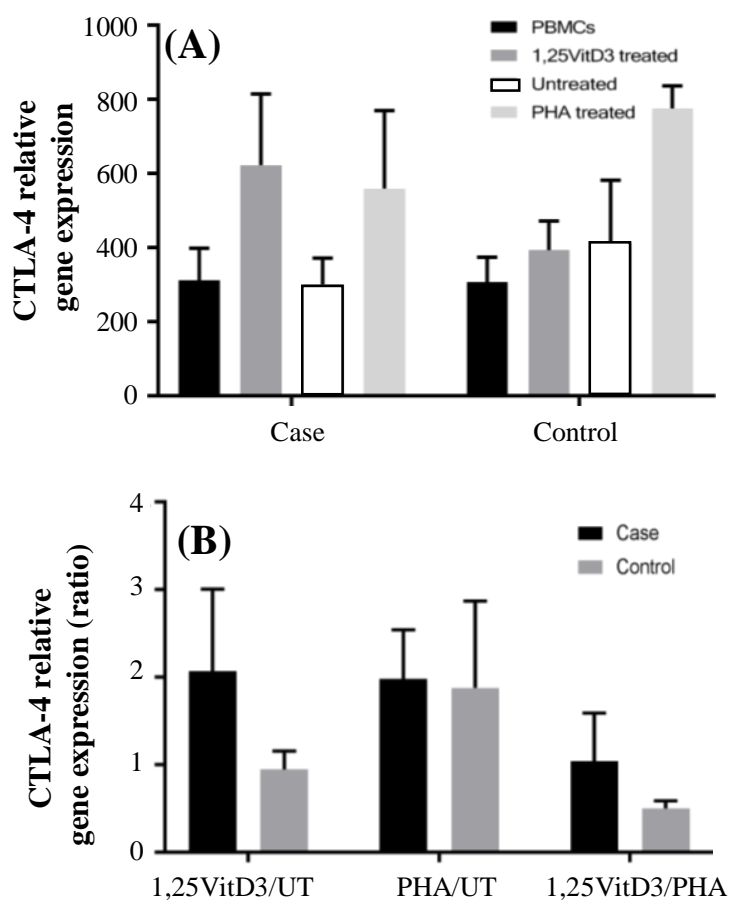

Fig. 5. CTLA-4 gene expression. CTLA-4 gene expression (A) and its ratio (B) in the presence of $1,25 \mathrm{VitD} 3$, PHA (as a positive control), and negative control (as a baseline) in PBMCs of patients with URPL and the controls. UT, untreated 


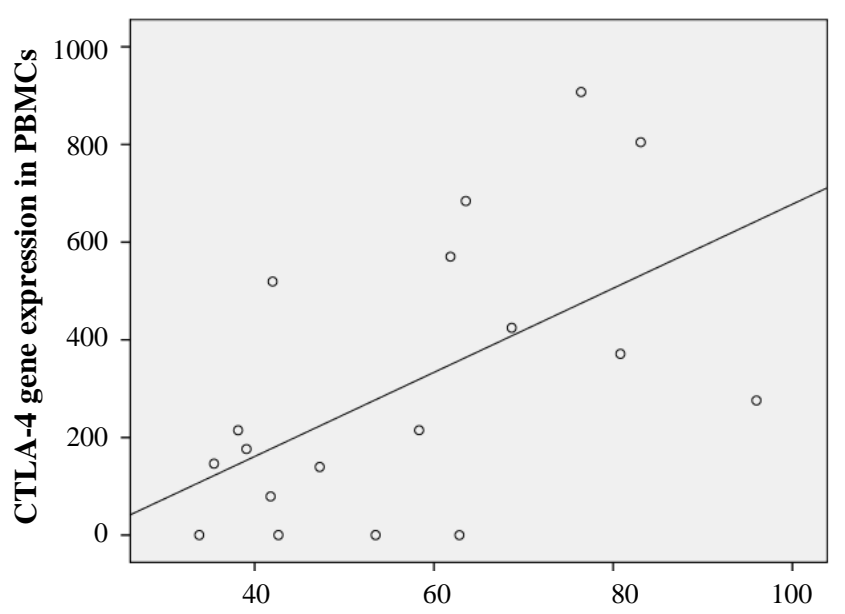

FOXP3 gene expression in PBMCs

Fig. 6. Direct significant correlation between FOXP3 and CTLA-4 gene expression in the control group.

women experiencing URPL compared to the control group (Figs. 1A, 2A, and 3A). This finding is in agreement with other studies, indicating that FOXP3 gene expression decreased in patients with pregnancy loss ${ }^{[60,65]}$. The results of the present study indicated that $1,25 \mathrm{VitD} 3$ treatment could significantly increase FOXP3 gene expression (Fig. 1B) in PBMCs of women with URPL. Besides, the reduced percentage of Tregs in PBMCs of women with URPL was observed and elevated upon treatment with 1,25VitD3 (unpublisheddata). The results of the present study indicated that $1,25 \mathrm{VitD} 3$ treatment could significantly increase FOXP3 gene expression (Fig. 1B) in PBMCs of women with URPL. Herein, we showed a reduction in the percentage of Tregs in PBMCs of women with URPL, and 1,25VitD3 treatment elevated the percentage of Tregs (unpublished date). It is probable that the reduction of Tregs in PBMCs of URPL women is closely related to the decreased expression of FOXP $3^{[35]}$. It is probable that the reduction of Tregs in URPL women is closely related to the decreased expression of FOXP $3^{[41]}$. Therefore, we speculate that $1,25 \mathrm{VitD} 3$ may increase the percentage of Tregs and FOXP3 gene expression in pregnancy as shown in other study ${ }^{[66]}$.

There are some contradictory results about the effects of 1,25VitD3 on Tregs numbers ${ }^{[67-69]}$. 1,25$(\mathrm{OH}) 2 \mathrm{D} 3$ may promote Tregs differentiation and enhance the frequency of activation-induced $\mathrm{FOXP}^{+}$ $\mathrm{T}$ cells, and this was dependent on the presence of IL-2 in culture. These $\mathrm{FOXP3}^{+}$Tregs expressed high levels of CTLA-4, an inhibitory receptor ${ }^{[67]}$. However, a comparable study using naïve murine $\mathrm{T}$ cells has suggested that 1,25-(OH)2D3 inhibits both IL-17 and Tregs differentiation in vitro. Mayne et al. ${ }^{[68]}$ have indicated that $1,25 \mathrm{VitD} 3$ could confer protection against an EAE model in mice through decreasing Th1 and Th17 (with abundant VDR transcripts). This study reflects that low VDR expression in $\mathrm{CD} 4^{+} \mathrm{FOXP} 3^{+}$ Tregs may allow them to escape sensitization to apoptotic signals, leading to unchnaged Tregs proportion in the presence of $1,25 \mathrm{VitD} 3$ in an EAE model. Some early studies have suggested that vitamin $\mathrm{D}$ has deleterious effects on allergic airway disease. VDR-deficient mice failed to develop experimental allergic asthma, leading the authors to suggest a role for vitamin $\mathrm{D}$ in driving Th2 inflammation in the airways ${ }^{[69]}$. Nevertheless, considerable interest remains in the therapeutic application in asthma, and examples of beneficial effects exist. The probable reason behind the lack of any significant difference between the ROR$\gamma \mathrm{t}$ gene expression in the case and control groups is that the regulation of the immune response by vitamin $\mathrm{D}$ is achieved through increasing FOXP3 gene expression and enhancing Tregs function, which results in the inhibition of inflammatory responses of Th17 cells, contributing indirectly in recurrent spontaneous abortion. In addition, according to our unpublished flowcytometry data, 1,25VitD3 up-regulated the differentiation of Tregs in vitro while did notaffect the Th17 cell differentiation. Therefore, we suppose that the lack of any significant effect on Th17 percentage comes from no impaction on ROR- $\gamma \mathrm{t}$ gene expression by $1,25 \mathrm{VitD} 3$, suggesting that $1,25 \mathrm{VitD} 3$ is an immunemodulatory agent regulating Tregs differentiation to ensure pregnancy progresses to term. Vitamin D could act to prevent recurrent abortion as a regulator agent of immune responses rather than an immunosuppressive of the inflammatory responses.

Our findings, for the first time, demonstrated that 1,25VitD3 enhanced GITR gene expression in PBMCs of women with URPL (Fig. 4B). GITR is a marker characteristic for Tregs. High level of GITR expression can be obtained in 72. Along with the regulation of Tregs reactivity, GITR induces co-stimulatory signals in Tregs involved in $\mathrm{T}$ cell proliferation and cytokine production $^{[72]}$. Our finding also indicated that there was a direct significant correlation between FOXP3 and CTLA-4 gene expression in the control group. Therefore, it can be concluded that Tregs $\mathrm{FOXP}^{+}{ }^{+} \mathrm{CTLA}^{+}$function may disrupt in patients with URPL. According to our results, $1,25 \mathrm{VitD} 3 \mathrm{had}$ no significant effect on CTLA-4 gene expression. Meanwhile, the evaluation of the effects of 1,25VitD3 on Tregs and Th17 cells and related signaling pathways involved in differentiation of Tregs and Th17 cells should be considered in future studies to understand more details of these.

To sum up, the present study revealed that $1,25 \mathrm{VitD} 3$ 
may directly affect the immunoregulatory mechanism through increasing FOXP3 and GITR gene expression rather than immunosuppression effect on Th17 cells. The present study was not without limitations, and we propose that future studies are needed to be performed with the larger sample size. Considering the role of Th17 and Tregs in pregnancy outcome, targeting this ratio may result in a successful pregnancy. Therefore, $1,25 \mathrm{VitD} 3$ may have a function in providing requirements for the anti-inflammatory state and promoting pregnancy maintenance. Determination of the optimal time and dosage of 1,25VitD3 are very important for a desirable clinical outcome.

\section{ACKNOWLEDGEMENTS}

We would like to thank the Vice-Chancellor for Research and Student Research Committee of Mashhad University of Medical Sciences, Mashhad, Iran for the financial support of the present study.

CONFLICT OF INTEREST. None declared.

\section{REFERENCES}

1. Heitmann RJ, Weitzel RP, Feng Y, Segars JH, Tisdale JF, Wolff EF. Maternal $\mathrm{T}$ regulatory cell depletion impairs embryo implantation which can be corrected with adoptive $\mathrm{T}$ regulatory cell transfer. Reproductive sciences 2017; 24(7): 1014-1024.

2. Robertson S. Knobil and Neill's Physiology of Reproduction. In: Petroff MG, Hunt JS. Immunology of pregnancy. UK: Elsevier; 2015. p. 1835-1874.

3 . Focus on recurrent miscarriage phenotypes. Fertility and sterility 2017; 107(1): 64-65.

4. Lee SK, Na BJ, Kim JY, Hur SE, Lee M, Gilman-Sachs A, Kwak-Kim J. Determination of clinical cellular immune markers in women with recurrent pregnancy loss. American journal of reproductive immunology 2013; 70(5): 398-411.

5. Tavasolian F, Abdollahi E, Samadi M. Association of the IL4R single-nucleotide polymorphism I50V with recurrent spontaneous abortion (RSA). Journal of assisted reproduction and genetics 2014; 31(7): 851856.

6. Rai R, Regan L. Recurrent miscarriage. The lancet 2006; 368(9535): 601-611.

7. Heuser C, Dalton J, Macpherson C, Branch DW, Porter TF, Silver RM. Idiopathic recurrent pregnancy loss recurs at similar gestational ages. American journal of obstetrics and gynecology 2010; 203(4): 343.e1-343.e5.

8. Aluvihare VR, Kallikourdis M, Betz AG. Regulatory T cells mediate maternal tolerance to the fetus. Nature immunology 2004; 5(3): 2660-271.

9. Kamali M, Hantoushzadeh S, Borna S, Neamatzadeh H,
Mazaheri M, Noori-Shadkam M, Haghighi F. Association between thrombophilic genes polymorphisms and recurrent pregnancy loss susceptibility in the Iranian population: a systematic review and meta-analysis. Iranian biomedical journal 2018; 22(2): 78-89.

10. Ghafourian Boroujerdnia M, Chinipardaz R. Endometrial granulated lymphocytes in women suffering spontaneous early pregnancy loss. Iranian biomedical journal 2002; 6(2 \& 3): 89-92.

11. La Rocca C, Carbone F, Longobardi S, Matarese G. The immunology of pregnancy: regulatory $\mathrm{T}$ cells control maternal immune tolerance toward the fetus. Immunology letters 2014; 162(1 Pt ): 41-48.

12. Wegmann TG, Lin H, Guilbert L, Mosmann TR. Bidirectional cytokine interactions in the maternal-fetal relationship: is successful pregnancy a TH2 phenomenon? Immunology today 1993; 14(7): 353-356.

13. Piccinni MP, Beloni L, Livi C, Maggi E, Scarselli G, Romagnani S. Defective production of both leukemia inhibitory factor and type 2 T-helper cytokines by decidual $\mathrm{T}$ cells in unexplained recurrent abortions. Nature medicine 1998; 4(9): 1020-1024.

14. Raghupathy R. Th 1-type immunity is incompatible with successful pregnancy. Immunology today 1997; 18(10): 478-482.

15. Riazi Rad FR, Ajdary S, Omranipour R, Alimohammadian $\mathrm{MH}$, Hassan ZM. Comparative analysis of $\mathrm{CD}^{+}$and $\mathrm{CD}^{+} \mathrm{T}$ cells in tumor tissues, lymph nodes and the peripheral blood from patients with breast cancer. Iranian biomedical journal 2015; 19(1): 35-44.

16. Wu L, Luo LH, Zhang YX, Li Q, Xu B, Zhou GX, Luan HB, Liu YS. Alteration of Th17 and Treg cells in patients with unexplained recurrent spontaneous abortion before and after lymphocyte immunization therapy. Reproductive biology and endocrinology 2014; 12: 74 .

17. Lee S, Kim J, Hur S, Kim C, Na B, Lee M, GilmanSachs A, Kwak-Kim J. An imbalance in interleukin-17producing $\mathrm{T}$ and Foxp ${ }^{+}$regulatory $\mathrm{T}$ cells in women with idiopathic recurrent pregnancy loss. Human reproduction 2011; 26(11): 2964-2971.

18. Wang WJ, Hao CF, Qu QL, Wang X, Qiu LH, Lin QD. The deregulation of regulatory $\mathrm{T}$ cells on interleukin-17producing $\mathrm{T}$ helper cells in patients with unexplained early recurrent miscarriage. Human reproduction 2010; 25(10): 2591-2596.

19. Lastovicka J. The phenotypic markers of $\mathrm{CD} 4^{+} \mathrm{CD} 25^{+} \mathrm{T}$ regulatory lymphocytes. Reseach in immunology 2013; 2013: $1-14$

20. Tang Q, Bluestone JA. The Foxp $3^{+}$regulatory T cell: a jack of all trades, master of regulation. Nature immunology 2008; 9(3): 239-244.

21. Tilburgs T, Roelen DL, van der Mast BJ, de GrootSwings GM, Kleijburg C, Scherjon SA, Claas FH. Evidence for a selective migration of fetus-specific $\mathrm{CD}^{+} \mathrm{CD} 25$ bright regulatory $\mathrm{T}$ cells from the peripheral blood to the decidua in human pregnancy. The journal of immunology 2008; 180(8): 5737-5745. 
22. Fontenot JD, Gavin MA, Rudensky AY. Foxp3 programs the development and function of $\mathrm{CD} 4^{+} \mathrm{CD} 25^{+}$ regulatory T cells. Nature immunology 2003; 4(4): 330336.

23. Corthay A. How do regulatory $\mathrm{T}$ cells work? Scandinavian journal of immunology 2009; 70(4): 326336.

24. Vignali DAA, Collison LW, Workman CJ. How regulatory T cells work. Nature reviews immunology 2008; 8(7): 523-532.

25. Aluvihare VR, Betz AG. The Role of Regulatory $T$ Cells in Materno-Fetal Tolerance. Immunology of Pregnancy. Germany: Springer; 2006.

26. Guerin LR, Prins JR, Robertson SA. Regulatory T-cells and immune tolerance in pregnancy: a new target for infertility treatment? Human reproduction update 2009; 15(5): 517-535

27. Korn T, Bettelli E, Oukka M, Kuchroo VK. IL-17 and Th17 cells. Annual review of immunology 2009; 27: 485-517.

28. van Hamburg JP, Tas SW. Molecular mechanisms underpinning $\mathrm{T}$ helper 17 cell heterogeneity and functions in rheumatoid arthritis. Journal of autoimmunity 2018; 87: 69-81.

29. Miossec P, Kolls JK. Targeting IL-17 and TH17 cells in chronic inflammation. Nature reviews drug discovery 2012; 11(10): 763-776.

30. Abdollahi E, Tavasolian F, Momtazi-Borojeni AA, Samadi M, Rafatpanah H. Protective role of R381Q (rs11209026) polymorphism in IL-23R gene in immunemediated diseases: A comprehensive review. Journal of immunotoxicology 2016; 13(3): 286-300.

31. Noack M, Miossec P. Th17 and regulatory $T$ cell balance in autoimmune and inflammatory diseases. Autoimmunity reviews 2014; 13(6): 668-677.

32. Nakashima A, Ito M, Shima T, Bac ND, Hidaka T, Saito S. Accumulation of IL-17-positive cells in decidua of inevitable abortion cases. American journal of reproductive immunology 2010; 64(1): 4-11.

33. Liu F, Guo J, Tian T, Wang H, Dong F, Huang H, Dong M. Placental trophoblasts shifted Th1/Th2 balance toward Th2 and inhibited Th17 immunity at fetomaternal interface. APMIS 2011; 119(9): 597-604.

34. Liu YS, Wu L, Tong XH, Wu LM, He GP, Zhou GX, Luo LH, Luan HB. Study on the relationship between Th17 cells and unexplained recurrent spontaneous abortion. American journal of reproductive immunology 2011; 65(5): 503-511.

35. Hosseini S, Shokri F, Ansari Pour S, Jeddi-Tehrani M, Nikoo S, Yousefi M, Zarnani AH. A shift in the balance of T17 and Treg cells in menstrual blood of women with unexplained recurrent spontaneous abortion. Journal of reproductive immunology 2016; 116: 13-22.

36. Bettelli E, Carrier Y, Gao W, Korn T, Strom TB, Oukka M, Weiner HL, Kuchroo VK. Reciprocal developmental pathways for the generation of pathogenic effector TH17 and regulatory T cells. Nature 2006; 441(7090): 235-238.

37. Yang H, Qiu L, Chen G, Ye Z, Lü C, Lin Q. Proportional change of $\mathrm{CD}^{+} \mathrm{CD} 25^{+}$regulatory $\mathrm{T}$ cells in decidua and peripheral blood in unexplained recurrent spontaneous abortion patients. Fertility and sterility 2008; 89(3): 656-661.

38. Somerset DA, Zheng Y, Kilby MD, Sansom DM, Drayson MT. Normal human pregnancy is associated with an elevation in the immune suppressive CD25 $5^{+}$ $\mathrm{CD}^{+}$regulatory T-cell subset. Immunology 2004; 112(1): 38-43.

39. Heyden E, Wimalawansa S. Vitamin D: Effects on human reproduction, pregnancy, and fetal well-being. The journal of steroid biochemistry and molecular biology 2018; 180: 41-50.

40. Prosser DE, Jones G. Enzymes involved in the activation and inactivation of vitamin D. Trends in biochemical sciences 2004; 29(12): 664-673.

41. Dabrowski F, Grzechocinska B, Wielgos M. The role of vitamin D in reproductive health - a Trojan horse or the golden fleece? Nutrients 2015; 7(6): 4139-4153.

42. Luk J, Torrealday S, Neal Perry G, Pal L. Relevance of vitamin D in reproduction. Human reproduction 2012; 27(10): 3015-3027.

43. Blomberg Jensen M, Gerner Lawaetz J, Andersson AM, Petersen JH, Nordkap L, Bang AK, Ekbom P, Joensen UN, Prætorius L, Lundstrøm P, Boujida VH, Lanske B, Juul A, Jørgensen N. Vitamin D deficiency and low ionized calcium are linked with semen quality and sex steroid levels in infertile men. Human reproduction 2016; 31(8): 1875-1885.

44. Young BE, Cooper EM, McIntyre AW, Kent T, Witter $\mathrm{F}$, Harris ZL, O'Brien KO. Placental vitamin D receptor (VDR) expression is related to neonatal vitamin D status, placental calcium transfer, and fetal bone length in pregnant adolescents. The FASEB journal 2014; 28(5): 2029-2037.

45. Knabl J, Vattai A, Ye Y, Jueckstock J, Hutter S, Kainer F, Mahner S, Jeschke U. Role of placental VDR expression and function in common late pregnancy disorders. International journal of molecular sciences 2017; 18(11): 2340.

46. Shahbazi M, Jeddi-Tehrani M, Zareie M, SalekMoghaddam A, Akhondi M, Bahmanpoor M, Sadeghi MR, Zarnani AH. Expression profiling of vitamin D receptor in placenta, decidua and ovary of pregnant mice. Placenta 2011; 32(9): 657-664.

47. Chang SH, Chung Y, Dong C. Vitamin D suppresses Th17 cytokine production by inducing C/EBP homologous protein (CHOP) expression. Journal of biological chemistry 2010; 285(5): 38751-38755.

48. Bubanovic I. 1 $\alpha, 25$-dihydroxy-vitamin-D3 as new immunotherapy in treatment of recurrent spontaneous abortion. Medical hypotheses 2004; 63(2): 250-253.

49. Deluca HF, Cantorna MT. Vitamin D: its role and uses in immunology. The FASEB journal 2001; 15(14): 2579-2585.

50. Ji J, Zhai H, Zhou H, Song S, Mor G, Liao A. The role and mechanism of vitamin D-mediated regulation of Treg/Th17 balance in recurrent pregnancy loss. American journal of reproductive immunology 2019; 81(6): e13112.

51. Pandey MK, Rani R, Agrawal S. An update in recurrent 
spontaneous abortion. Archives of gynecology and obstetrics 2005; 272(2): 95-108.

52. Krieg S, Fan X, Hong Y, Sang QX, Giaccia A, Westphal L, Lathi RB, Krieg AJ, Nayak NR. Global alteration in gene expression profiles of deciduas from women with idiopathic recurrent pregnancy loss. Molecular human reproduction 2012; 18(9): 442-450.

53. Pandey MK, Thakur S, Agrawal S. Lymphocyte immunotherapy and its probable mechanism in the maintenance of pregnancy in women with recurrent spontaneous abortion. Archives of gynecology and obstetrics 2004; 269(3): 161-172.

54. Omwandho CA, Tinneberg HR, Tumbo-Oeri AG, Roberts TK, Falconer J. Recurrent pregnancy losses and the role of immunotherapy. Archives of gynecology and obstetrics 2000; 264(1): 3-12.

55. Saito S, Nakashima A, Shima T, Ito M. Th1/Th2/Th17 and regulatory T-cell paradigm in pregnancy. American journal of reproductive immunology 2010; 63(6): 601610.

56. Teles A, Thuere C, Wafula PO, El-Mousleh T, Zenclussen ML, Zenclussen AC. Origin of Foxp $3^{+}$cells during pregnancy. American journal of clinical and experimental immunology 2013; 2(3): 222-233.

57. Jin LP, Chen QY, Zhang T, Guo PF, Li DJ. The $\mathrm{CD} 4{ }^{+} \mathrm{CD} 25$ bright regulatory $\mathrm{T}$ cells and CTLA-4 expression in peripheral and decidual lymphocytes are down-regulated in human miscarriage. Clinical immunology 2009; 133(3): 402-410.

58. Kwak-Kim JY, Chung-Bang HS, Ng SC, Ntrivalas EI, Mangubat CP, Beaman KD, Beer AE, Gilman-Sachs A. Increased $\mathrm{T}$ helper 1 cytokine responses by circulating $\mathrm{T}$ cells are present in women with recurrent pregnancy losses and in infertile women with multiple implantation failures after IVF. Human reproduction 2003; 18(4): 767-773.

59. Saito S, Sasaki Y, Sakai M. CD $4^{+} \mathrm{CD} 25$ high regulatory $\mathrm{T}$ cells in human pregnancy. Journal of reproductive immunology 2005; 65(2): 111-120.

60. Mei S, Tan J, Chen H, Chen Y, Zhang J. Changes of $\mathrm{CD} 4{ }^{+} \mathrm{CD} 25$ high regulatory $\mathrm{T}$ cells and FOXP3 expression in unexplained recurrent spontaneous abortion patients. Fertility and sterility 2010; 94(6): 2244-2247.

61. Darmochwal-Kolarz D, Leszczynska-Gorzelak B, Rolinski J, Oleszczuk J. The immunophenotype of patients with recurrent pregnancy loss. European journal of obstetrics and gynecology and reproductive biology 2002; 103(1): 53-57.

62. Vassiliadou N, Searle R, Bulmer J. Immunoregulatory activity of decidua in spontaneous early pregnancy loss. Human reproduction 1999; 14(9): 2252-2256.

63. Abdollahi E, Tavasolian F, Ghasemi N, Mirghanizadeh
SA, Azizi M, Ghoryani M, Samadi M. Association between lower frequency of R381Q variant (rs11209026) in IL-23 receptor gene and increased risk of recurrent spontaneous abortion (RSA). Journal of immunotoxicology 2015; 12(4): 317-321.

64. Prots I, Skapenko A, Wendler J, Mattyasovszky S, Yoné CL, Spriewald B, Burkhardt H, Rau R, Kalden JR, Lipsky PE, Schulze-Koops H. Association of the IL4R single-nucleotide polymorphism I50V with rapidly erosive rheumatoid arthritis. Arthritis and rheumatism 2006; 54(5): 1491-500.

65. Saifi B, Rezaee SA, Tajik N, Ahmadpour ME, Ashrafi M, Vakili R, Soleimani Asl S, Aflatoonian R, Mehdizadeh M. Th17 cells and related cytokines in unexplained recurrent spontaneous miscarriage at the implantation window. Reproductive biomedicine online 2014; 29(4): 481-489.

66. Vijayendra Chary A, Hemalatha R, Seshacharyulu M, Vasudeva Murali M, Jayaprakash D, Dinesh Kumar B. Vitamin D deficiency in pregnant women impairs regulatory $\mathrm{T}$ cell function. The journal of steroid biochemistry and molecular biology 2015; 147: 48-55.

67. Jeffery LE, Burke F, Mura M, Zheng Y, Qureshi OS, Hewison M, Walker LS, LAmmas DA, Reza K, Sansom DM. 1,25-Dihydroxyvitamin D3 and IL-2 combine to inhibit $\mathrm{T}$ cell production of inflammatory cytokines and promote development of regulatory $\mathrm{T}$ cells expressing CTLA-4 and FoxP3. The journal of immunology 2009; 183(9): 5458-5467.

68. Mayne CG, Spanier JA, Relland LM, Williams CB, Hayes CE. 1,25-Dihydroxyvitamin D3 acts directly on the $\mathrm{T}$ lymphocyte vitamin $\mathrm{D}$ receptor to inhibit experimental autoimmune encephalomyelitis. European journal of immunology 2011; 41(3): 822-832.

69. Wittke A, Weaver V, Mahon BD, August A, Cantorna MT. Vitamin D receptor-deficient mice fail to develop experimental allergic asthma. The journal of immunology 2004; 173(5): 3432-3436.

70. Li Z, Mahesh SP, Kim BJ, Buggage RR, Nussenblatt RB. Expression of glucocorticoid induced TNF receptor family related protein (GITR) on peripheral T cells from normal human donors and patients with non-infectious uveitis. Journal of autoimmunity 2003; 21(1): 83-92.

71. Heikkinen J, Möttönen M, Alanen A, Lassila O. Phenotypic characterization of regulatory $\mathrm{T}$ cells in the human decidua. Clinical and experimental immunology 2004; 136(2): 373-378.

72. Placke T, Kopp HG, Salih HR. Glucocorticoid-induced TNFR-related (GITR) protein and its ligand in antitumor immunity: functional role and therapeutic modulation. Clinical and developmental immunology 2010; 2010: 239083. 